\title{
Debilidades dentro de los procesos de mundialización textil y relación con la RSE a través de un análisis DELPHI: ética o estética
}

\author{
Weaknesses within the processes of globalization \\ in the textile sector and their relation to CSR through \\ a DELPHI analysis: ethical or aesthetic
}

\author{
ARTURO LUQUE GONZÁLEZ*, JUAN HERNÁNDEZ ZUBIZARRETA**, \\ CARMEN DE PABLOS HEREDERO* \\ *Universidad Rey Juan Carlos, **Universidad del País Vasco
}

Artículo recibido: 19 diciembre 2015

Solicitud de revisión: 01 febrero 2016

Artículo aceptado: 28 julio 2016

Resumen

El objetivo de esta investigación es detectar las principales debilidades del sector textil en relación con la responsabilidad social empresarial y proponer medidas que contribuyan a superarlas. Partimos de que las asimetrías y relaciones generadas necesarias para fabricar prendas textiles en el contexto internacional no son imputables a una sola circunstancia. Es igualmente entendible que sus soluciones pasen por la identificación y la transversalidad de dichas circunstancias. En la presente investigación, lo llevamos a cabo mediante la de la recolección de opiniones y soluciones expresadas por diferentes participantes, y a través de un análisis Delphi, para conocer cuáles son los puntos críticos y vulnerabilidades del sector, y la posterior identificación de sus debilidades, tras el análisis de las respuestas de dos paneles de expertos a dos cuestionarios multidisciplinares, con preguntas desarrolladas sobre las hipótesis planteadas.

Palabras clave: globalización, responsabilidad social corporativa, empresas transnacionales, corrupción, legislación.

\begin{abstract}
The objective of this research is to diagnose the main weakness in the textile industry according to Corporate Social Responsibility and provide measures that contribute to improve the situation. Asymmetries and the relationships required to manufacture textiles in the international context are not attributable to a single circumstance, hence it is also understandable that their solutions require of the identification and the transversal analysis derived from opinions and solutions coming from different participants to know what the critical sector vulnerabilities are through a Delphi analysis and subsequent identification of
\end{abstract}


weaknesses after analysing the responses coming from two expert panels by making use of two multidisciplinary questionnaires containing open questions.

Keywords: Globalization, corporate social responsibility, transnational companies, corruption, legislation.

\section{AGRADECIMIENTOS}

Este proyecto de investigación nunca podría haberse realizado sin la aportación de todos los expertos que han colaborado de manera altruista y desinteresada, aunque no por ello con menor dedicación, a tenor de las casi 450 hojas de respuestas -cuantitativas y cualitativas- recibidas de los participantes para ser objeto de discusión académica y análisis. Destacando a Fernando Oliván (director del Observatorio Euromediterráneo, ex-miembro de la CPI y profesor de la URJC), Isidor Boix (secretario de Acción Sindical Internacional de FITEQA-CC.OO), Octavio Granado (experto en financiación pública y ex secretario de Estado de Seg. Social), Michael Addo (investigador en la Universidad de Exeter, Devon, Reino Unido, y miembro del Grupo de Trabajo sobre Empresas y Derechos Humanos de las Naciones), Gabriel Flores Sánchez (investigador del Instituto Complutense de Estudios Internacionales), Aleida Hernández (investigadora de la Universidad Nacional Autónoma de México), Juan Andrés Cano (ceo de Value4Chain), María del Mar Maira Vidal (Investigadora en la Universidad de Valladolid), Rodrigo Martín (Investigador en la URJC, ex magistrado del TSJM y miembro del Consejo Académico de Gómez-Acebo \& Pombo), Alejandro Goldberg (investigador en CONICET), Amaya Apesteguía (OCu), Ibon Maza (BabyAuto), Enrique Dussel (investigador de la Universidad Nacional Autónoma de México y coordinador de estudios en CEPAL y oIT), Jesús García Luengos (coordinador del think tank RESET Research on Security and Transnational Governance), Jordi Bonet (catedrático de la uB en derecho internacional público), José Manuel Pureza (investigador en la Universidad de Coimbra Y CES, arbitro CPA y de Naciones Unidas sobre el mar), Roberto Toscano (investigador de relaciones internacionales y RSE, además de ex embajador de Italia en India e Irán), Juan Manzanedo (Ceo de Logisfashion), Juan Pérez Ventura (Ceo de El Orden Mundial en el S. xxi), Paula Alves (empleada de Inditex desde hace 24 años y Secretaria del Sector Textil-Piel de FITAGugT), Santi Mallorquí (Ceo de organic Cotton COLours), Martim Gemzell (Warontwant), Gema Gómez (Ceo slow fashion spain), Carmen Gómez-Cotta (eтHIC), Enrique Palazuelos Manso (catedrático de economía aplicada en la Universidad Complutense de Madrid), Michael Tamvakis (investigador en 
Cass Business School), Eva García (ecoology), Alejandro Dulitzky (investigador en Universidad Nacional de San Martín), Juan Torres (catedrático de Economía Aplicada en la Universidad de Sevilla y miembro del comité científico de ATTAC), Amparo Merino Segovia (investigadora en la Universidad de Castilla la Mancha), Gonzalo Berrón (Fes Fundación Friedrich Ebert), Alejandro Teitelbaum (escritor, abogado y representante de la Federación Internacional de Derechos Humanos y de laAsociaciónAmericana de Juristas ante naciones unidas), Carmen Silla (Jeanologia), Antonio Baylos (catedrático de Derecho del Trabajo y de la Seguridad Social en la Universidad de Castilla la Mancha), Álvaro Orsatti (CSA), Monika Kemperle (Industrial Global Union), Mariano Aguirre (director del Norwegian Peacebuilding Resource Centre NOREF en Oslo), Pablo José Martínez Osés (investigador y coordinador de la Campaña estatal Pobreza Cero y miembro de 2015ymas), Iñaki Barcena (catedrático de Ciencia Política en la Universidad del País Vasco), Virginia Rondeel (Moda Sostenible BCN), Marta Castells (CITYC), Enrique Guerrero Salom (profesor y eurodiputado), Javier Chércoles (investigador en la Universidad de Dhaka y director de riesgos en Associated British Foods plc), Esteban Kaipl (investigador en Universidad de Litoral), Iratxe Arteagoitia y Eva Kreisler (setem \& CleAn Clothes CAMPAign), José Miguel Mulet (Investigador del Instituto de Biología Molecular y Celular de Plantas IBмCP de Valencia), Amanda Cattermole (CATtermoleconsulting), Liliane Spendeler (amigos de la tierra), Cheryl S. Watson (investigadora en University of Texas Medical Branch), Isabel Soriano (AITEX), Dolores Romano (investigadora independiente/Ecologistas en acción),Antonio Solé Cabanes (ASOLEGIN), Oscar Miralles (investigador independiente), Xavier Giménez Font (investigador de Química Ambiental en la Universidad de Barcelona), Raimon Guitart (investigador en toxicología en Universidad Autonoma de Barcelona), Ferran Ballester (coordinador del área de Ambient i Salut del Centro Superior de Investigación en Salud Pública csisP), Stephane Horel (independiente) y Carlos de Prada (Fodesam).

\section{INTRODUCCIÓN}

El actual modelo de industria textil se apoya en la elaboración y análisis de información generada a través de diferentes canales -muchos de ellos en tiempo real- que poseen las diferentes empresas transnacionales (ET) textiles así como sus filiales, proveedores, empresas externalizadas, etc. (Buxmann, 1999; Gil y otros, 2008). Actualmente se establecen relaciones 
con miles de proveedores - con capacidad de acercar estos a los mercadosaprovechando una eficiente respuesta (Guercini y Runfola, 2004). Es necesario considerar los riesgos entre negocios y países (Echezarraga y Jarillo, 2001), así como el «estudio sobre las condiciones de entrada de productos de terceros países, y la determinación del cumplimiento de la normativa legal y reglamentaria de la Unión Europea» (Jódar, 1998: 14). El crecimiento de la competencia mundial, la aparición de nuevos riesgos, las demandas por parte de la sociedad, además de la aparición de actitudes consustanciales a la fabricación textil, como las que señala Heuskel y Costa (1999), han forzado a los proveedores internos a competir agresivamente en un mercado abierto por conseguir el próximo pedido. De ahí, la necesidad de profundizar en los objetivos de este trabajo: conocer la falta de conciencia de muchas empresas y gobiernos ante el continuo y sistemático incumplimiento de las normativas laborales, a pesar de las recomendaciones de reconocidas instituciones como la Organización Internacional del Trabajo (OIT), así como la afectación a los derechos humanos y a la ética, debido al empuje de sistemas económicos basados en el crecimiento ilimitado y al análisis de nuevos métodos de producción y gestión empresarial ultrarrápido. Para Value4Chain ${ }^{1}$ :

Quizá veamos mayor innovación en países en desarrollo que con las nuevas tecnologías podrán competir con modelos tradicionales. Esto podría cambiar el escenario de las cadenas de valor, en donde el valor agregado se captura en la marca, en la comercialización, y no tanto en la producción, que es donde más gente se ve afectada (2015).

Muchas variables deben ser analizadas para conocer cómo se trabaja en este sector, por ejemplo la identificación de las competencias esenciales en las empresas (Prahalad y Hamel, 1990) a la hora de realizar una actividad. Destaca el entorno y las herramientas de las que se dispone, apoyadas a su vez por la evolución tecnológica de sistemas de productividad gestionadas mediante nuevos modelos de organización empresarial (Hess y Yeung 2006; Christopher y otros, 2006). Por otro lado existen otras variables no tan organizativas -aunque no por ello menos institucionalizadascomo son los procesos de corrupción. A modo de ejemplo, podemos señalar la corrupción legalizada, sistémica, la meta corrupción, la generada de manera endógena, el nepotismo, la regulación «a medida» para que el resto de

1 J.A Cano (Value4Chain), R. Toscano, J. Chércoles, C. S. Watson (julio de 2015). Documentación propia extraída de un análisis DELPHI/entrevista a los autores por (A. Luque, entrevistador) e incluida en la tesis «Gestión y control de la cadena de valor dentro del sector textil en países en vías de desarrollo, hacia los límites de la logística y el outsourcing: Ética o Estética». 
actividades quede ad hoc sin regular y "jugar el partido» en ese espacio donde el estado legisla no legislando (Sánchez Barrilao, 2004), y así todo tipo de intereses particulares con capacidad de afectación. Según Ziegler, relator especial de la onu para el Derecho a la Alimentación entre los años 2008 y 2011, en Bangladesh «[...]no se aplica ningún reglamento de higiene, ninguna ley salarial. Los sindicatos están prohibidos. La contratación y el despido se efectúan en función de las fluctuaciones de los encargos procedentes de Nueva York, Londres, Hong Kong o París» (2013: 207).

Para Kahhat (2005) y The Globe and Mail (2005), la corrupción se ve ahora como una de las causas principales del subdesarrollo. En palabras de Toscano (2015): «como han revelado repetidos casos, sobre todo en Bangladesh, los abusos en términos laborales, sociales y medioambientales, y de seguridad siguen a pesar de los reglamentos en vigor, a causa de un alto nivel de corrupción». Estas situaciones han llevado a dilemas como que una empresa asuma un determinado grado de responsabilidad pero sus miembros no -desde trabajadores hasta ejecutivos plenipotenciarios-, asistiendo con ello al deterioro moral, tanto individual como empresarial. «Una enorme fábrica textil de ocho pisos donde trabajaban casi cuatro mil personas es, sobre todo, responsabilidad de la codicia y la corrupción, como muchas otras en todo el mundo» (Rendueles y Marlasca, 2013).

Cabe preguntarnos ¿De dónde venimos y a dónde vamos? ¿Qué es lo que queremos para nuestras empresas y sociedades? Como señala Chércoles (2015) «luchar contra la corrupción debería ser parte de cualquier estrategia de Rsc que se considere sostenible».

De ahí que sea necesario profundizar en el concepto de responsabilidad social empresarial, RSE, estableciendo como punto de partida su carácter social. La RSC se asume por la empresa ante la sociedad y va más allá de la ley, aunque no debe de ser sustitutiva de la misma y mucho menos travestida. Debe adquirir sentido de moralidad y por tanto de responsabilidad. La integridad moral constituye el alma de toda organización empresarial aunque por sí sola no es lo suficientemente persuasiva, ejemplarizante o disuasoria como para solucionar todas las contingencias que pueden aquejar a la organización. La flexibilidad que caracteriza a ciertos entornos empresariales hace aflorar lo que Román (2004) denomina «corrosión del carácter». La empresa debe responder a las necesidades y expectativas que la sociedad le demanda, entre las que se encuentran una reputación no invasiva asentada en cánones de solidaridad, sensibilidad, políticas éticas, responsabilidad, imagen social y lo que es más importante, legalidad, adquiriendo un nuevo papel socializador de acompañamiento. 
Las empresas son sujetos activos de la gobernanza global (Risse, 2002; Wolft, 2005). De ahí que las políticas de Rse deban de desplegarse en lugares donde existan legislaciones creíbles con capacidad de ser reclamadas y ejercidas sin subterfugios - responsabilidad legal- así como mediante su toma de conciencia, a través de diferentes acciones como pueden ser de caridad, filantropía, fines sociales o la responsabilidad moral de la empresa, que aunque siempre son deseables nunca son de obligado cumplimiento, debido a la discrecionalidad de las mismas por parte de la propiedad o de sus directivos. Cabe destacar que cada vez existen más grupos de presión que velan por un entorno natural que permanece en una evidente posición de debilidad, y logran convertir su presión social en normativa asumida por parte de la empresa. De hecho, los consumidores, a través de sus acciones y gustos, se decantan por empresas comprometidas con el medio ambiente (Gildia, 1995; Zaman y otros, 1996). El comportamiento de los consumidores «[...] puede ser socialmente valioso, dado que ayuda a disciplinar el comportamiento social de las empresas. Sin embargo, para que la presión de los consumidores sea efectiva, es necesario que estos tengan acceso a medidas fiables sobre el comportamiento social de las empresas» (Calveras y Ganuza, 2004: 4).

Se debe analizar la RSE en la cadena de valor, cómo ha cambiado la relación entre proveedores, subcontratistas y distribuidores, así como la relación del nuevo paradigma industrial en continuo movimiento con los procesos de globalización. Es importante conocer cómo la empresa -si es que lo hace- asegura que sus productos cumplan unos estándares de producción y externalización, implicando a toda la organización hasta el punto de hacerla sostenible, evitando posibles rupturas entre las condiciones de diseño de un producto y las condiciones de realización, con especial atención a su entorno, generando a su vez nuevos interrogantes. Como señala Grzybowski:

Reconvertir el sistema económico mundial en un modo de producción más respetuoso con el medio ambiente aportaría, naturalmente, enormes beneficios económicos a largo plazo. Pero, a corto plazo, requeriría considerables inversiones para renovar las estructuras de producción, de transporte y de suministro de energía, lo que ralentizaría la salida de la pobreza de millones de individuos (2012: 118).

Esta reconversión, como solución, cuenta con predisposiciones poco favorables por parte de accionistas (empresas) y mercados, que en general son más cortoplacistas. Watson (2015), consultada experta internacional en biología molecular y toxicología de la Universidad de Texas, lo expresa muy 
francamente, «es triste decir que no confío en las motivaciones de muchas de estas industrias [textiles, alimentarias] cuyo fondo consiste en una línea inmediata de ganancias para sus accionistas, esa es su única preocupación». Resulta evidente la necesidad de un análisis del entorno -político, legal, de ubicación, ONG's, diplomático, cultural, migratorio, climático, energético- a la hora de desarrollar una acción empresarial global dentro del sector textil; y de ahí que ello se convierta para nosotros en objeto de estudio a través de sus debilidades.

Tenemos a la vista la finalidad de responder a las condiciones en las que se da la gestión y producción textil en el marco de países en vías de desarrollo, así como la afectación de la actividad allí radicada y la relación de fuerzas con otros países y condicionantes hegemónicos. Nuestro objetivo con esta investigación es detectar las principales debilidades del sector textil, en relación a la responsabilidad social empresarial, y proponer medidas que contribuyan a superarlas. El trabajo se centra en el análisis de información privilegiada sobre las debilidades, recibida de un conjunto de 55 expertos de reconocido prestigio. Proponemos un análisis de las respuestas recibidas a las preguntas abiertas, promoviendo con ello ideas propias y profundizando a través del conocimiento multidisciplinar, con vistas privilegiadas de los participantes dentro de cada una de sus respectivas áreas de conocimiento y experticia, de manera cualitativa.

\section{METODOLOGÍA}

Es necesario analizar desde cualquier vertiente, incluida la empírica, los protocolos que existen, metodología de trabajo actual, riesgos y tendencias internacionales de un desarrollo industrial vinculado a la eliminación de fronteras bajo el paraguas de los procesos de mundialización. Entendemos que el método normalizado propuesto por еIRMA ${ }^{2}$ (European Industrial Research Management Association) junto con la entrevista a expertos es el método apropiado de análisis.

2 La European Industrial Research Management Association - EIRMA (Asociación Europea para la Administración de la Investigación Industrial) tiene como fin ayudar a las empresas a mejorar la gestión y organización de sus actividades de innovación e I+D. Se trata de una organización, sin ánimo de lucro, creada en 1966 gracias a la iniciativa conjunta de la industria europea y la OCDE (Organización para la Cooperación y el Desarrollo Económicos), dedicada a promover el intercambio abierto de experiencias entre profesionales de reconocido prestigio. 
Para la elaboración de este proyecto se han utilizado dos técnicas de investigación que conjugan la perspectiva cualitativa: (i) la entrevista y (ii) la técnica Delphi, según Ruiz Olabuénaga y Ispizua, (1989) y del Rincón y otros (1995), realizadas en dos paneles de expertos multidisciplinares.

\subsection{La entrevista}

La entrevista, que en este caso se contesta de forma escrita, ha permitido conocer en detalle el punto de vista de los participantes y se ha sintetizado en un análisis de debilidades (Strauss y Corbin, 1990).

La articulación de nuevos modelos explicativos generados y puestos a disposición de la sociedad civil y mercantil, no pueden llevarse a cabo con las mismas herramientas e interconexiones que utilizan actualmente los agentes implicados dentro de los procesos textiles. Por eso, es primordial acudir a una metodología transversal que ponga en contacto a los diferentes agentes implicados que o bien se encuentran a kilómetros de distancia o bien permanecen desconectados entre ellos, al no estar dentro de sus campos de acción inmediata.

Es necesario valorar la disfunción de manera global y dar soluciones compartidas ante circunstancias multidisciplinares. Para llegar a soluciones adecuadas se deben identificar con claridad los problemas -y factores- teniendo en cuenta que cualquier debilidad dentro de la cadena de valor y círculos relacionados que gravitan alrededor de toda la pirámide textil conviertan el sistema en más vulnerable.

Las soluciones que se buscan serán objeto del desarrollo de un nuevo marco de trabajo y desarrollo industrial, en el que todas las partes puedan sacar provecho de una fructífera relación, mediante el cumplimiento de las exigencias de dignidad humana y de control hacia los agentes implicados en la actividad. Asumimos la aparición de nuevos métodos de investigación con capacidad de innovar, que permiten desarrollar nuevas teorías y poner en entredicho muchos de los modelos actuales, además de aportar diferentes perspectivas ante una contingencia determinada inclusive en áreas de incertidumbre o de falta de evidencia empírica (Arias, 2003; Pill, 1971). 


\subsection{Delphi}

El método Delphi es un procedimiento prospectivo que tiene la finalidad de recabar información a través de la participación de un grupo de expertos, teniendo como base la discusión de un problema definido. Es un método de estructuración de un proceso de comunicación grupal, que tiene un resultado efectivo a la hora de permitir a un grupo de individuos, como un todo, tratar un problema complejo (Linstone y Turoff, 1995). Según Mengual (2011) un individuo en particular tiende a poseer menor fiabilidad que la de un grupo homogéneo de personas en igualdad de condiciones, siendo a la vez idóneo, como señala Vélez Pareja (2002), para el estudio de temáticas en las cuales la obtención de información tanto del pasado como del futuro no se encuentre de forma clara. El método Delphi es, por ello, un método idóneo para la obtención de información donde se dan estas circunstancias.

La técnica Delphi, a diferencia de otras técnicas cualitativas tales como los grupos focales o los grupos nominales, permite obtener información y opiniones de sujetos físicamente alejados, y posibilita la generación de ideas con respuestas abiertas, de forma bien estructurada y con un componente cualitativo añadido (Lunas Huertas y otros, 2006).

La formación generada por un grupo es mayor que la que dispone el participante con mayor experiencia y más preparado del grupo, el número de factores y condicionamientos evaluados por un grupo es mayor que si se hiciera de manera individual.

Para elaborar el procedimiento con éxito, confluyeron diferentes condicionantes como la elaboración del cuestionario que sería respondido por los expertos y la elección de estos mismos. Esto iría acompañado de sucesivas rondas de comunicación teniendo en cuenta la complejidad de contar con la participación de expertos en diferentes idiomas y husos horarios.

\subsection{Proceso seguido}

Después de identificar el problema de investigación se ha optado por recurrir a un amplio panel de participantes, con áreas de conocimiento diferentes, para intentar cubrir todos los flancos de la hipótesis y profundizar en el objeto de estudio. Se han utilizado principalmente las publicaciones existentes, poniendo especial atención a lo que se ha querido analizar y al cómo, ya no sólo cualitativamente, sino considerando la fuente de infor- 
mación. Por ejemplo, no es lo mismo la respuesta dada por el departamento de prensa de una organización, que la opinión directa de un experto con independencia financiera, o profesional acreditado; en muchos casos, las respuestas están prediseñadas, sobre todo en grandes compañías que facilitan idénticas respuestas ante problemáticas diferentes.

Fue determinante la elaboración de las preguntas, teniendo en cuenta la capilaridad de las mismas, así como las fuerzas lógicas que pueden modificar la graduación de sus respuestas. Atendiendo a los diferentes ejes analizados fueron estructuradas y precisadas -directas, indirectas, de investigación, específicas, clave, etc.-, traduciendo en esas preguntas los objetivos, hipótesis y cuestiones de la investigación (Valles, 2014), y relacionando las mismas con los factores que son necesarios para articular los sistemas de producción textil internacional. A continuación, los cuestionarios fueron enviados a los participantes.

«El investigador elabora a partir de las respuestas recibidas el segundo cuestionario, muchas veces ya de respuestas cerradas que posibilitan un tratamiento estadístico de las respuestas del grupo» (Martínez Piñero, 2003: 452). Puede enviarse otra ronda de cuestionarios e información adicional si fuera necesario, o no, cuando el grado de consenso sea amplio o cuando se observe que este no podrá ser mayor, como indica Fernández-Ballesteros (1995). No hubo un número de consultas fijo preconcebido.

\subsection{Modelo de cuestionario}

La herramienta seleccionada para la recopilación de información cualitativa objeto de esta investigación fue el cuestionario. La información fue obtenida a través de preguntas abiertas con el objetivo de profundizar en el punto vista de cada panelista sobre el sector textil desde diferentes prismas y áreas de conocimiento a través de sus debilidades. Uno de los retos era evitar la «apatía o stress indirecto» del grupo de invitados, ya que aunque la mayoría se mostraron receptivos cuando se les planteó el proyecto, en muchos de los casos ya advirtieron previamente de su falta de tiempo por lo apretado de sus agendas. Esto hizo explorar los límites del método hasta encontrar un equilibrio más alineado con nuestro estudio y sus necesidades.

El primero de los cuestionarios constó de 15 preguntas abiertas orientadas a la Rse, globalización, corrupción, conciencia empresarial, protección de los trabajadores, riesgos, empuje del consumidor, ong's, etc., elaborado 
a través de un modelo de entrevista escrita, basándonos en la literatura existente así como en entrevistas personales realizadas con otros expertos y profesionales no participantes. El segundo de los cuestionarios fue de 11 preguntas abiertas orientadas a expertos en riesgos químicos, tóxicos, agencias de evaluación, tintes textiles, etc., con la salvedad de que cuatro de las preguntas abiertas eran comunes entre ambos paneles.

Después de una primera ronda de cuestionarios enviados y recibidos, en nuestro caso entre el 01/05/2015 y el 30/07/2015 -con algún retraso no pactado pero previsto- se analizaron de manera cualitativa las respuestas dadas a las 15 preguntas abiertas de expertos en RSE, legislación, globalización, representación colectiva de trabajadores, así como las 11 preguntas abiertas realizadas a expertos químicos y riesgos. Luego de analizadas, sus consideraciones fueron añadidas alrededor de un DAFO, mostrándose en este trabajo las debilidades con una finalidad, la «obtención de una opinión grupal fidedigna a partir de un conjunto de expertos» (Landeta Rodríguez, 2002: 39).

\section{RESULTADOS}

Finalizada la etapa de envío y recogida de datos en ambas rondas, decidimos utilizar sólo los de la primera, ya que de 55 cuestionarios recibidos, pasamos a recibir en la segunda sólo 12, las cuales contenían prácticamente la posición inicial. En el procedimiento se les explicó que en caso de no responder a las rondas sucesivas, se mantendrían las valoraciones iniciales. Se analizaron cualitativamente los datos recibidos de las respuestas abiertas. A continuación se muestra un análisis de las debilidades con la finalidad de realizar una fotografía real del sector textil internacional. Se han analizado todas y cada una de las posiciones de los expertos participantes.

\subsection{Resultados cualitativos: debilidades}

Las debilidades identificadas en el sector textil que los expertos consultados han considerado más relevantes, se muestran agrupadas en distintos bloques: debilidades políticas y legales, económicas, sociales y tecnológicas (PEST), con la finalidad de recoger aspectos centrales y del entorno textil de una manera transversal y optimizar la comprensión de la lectura. 


\section{Políticas y legales}

- Normativa existente que se incumple (orT). Mecanismos internacionales débiles y falta de control judicial que asegure su cumplimiento. A nivel local, menor capacidad judicial en países subdesarrollados o en vías de desarrollo.

- Ausencia de tribunales internacionales que sancionen a las empresas por incumplimientos en la cadena de valor, además estos tribunales están sujetos a intereses de lobbies y et's.

- La hipotética creación de un Tribunal Internacional para las ET sería efectiva siempre que se unificaran normas y sanciones. Es probable que el escenario internacional no lo permitiera pues hay intereses de países poderosos que entran en contradicción, sesgos, influencias, problemas de operatividad, además de inconmensurable carga de trabajo. A modo de apunte, ¿Qué pasa con países como Alemania que no reconocen el crimen corporativo?

- Dificultad para imputar a las et costes sanitarios atribuibles a sustancias químicas utilizadas en sus productos y de procesos que pueden ser perjudiciales para la salud. El poder de los lobbies no va a permitir imputaciones generalizadas en relación a los costes producidos por la toxicidad de sus productos -exposición directa como inadvertida- desarrollándose largos y costosos procesos judiciales.

- Impagos de indemnizaciones justas y disuasorias por los daños causados o los incumplimientos de normas básicas de seguridad laboral de las Eт.

- Falta de democracia y protección internacional para las organizaciones y personas que luchan por las libertades básicas y los derechos humanos en países productores textiles.

- Ex metrópolis coloniales necesitan corrupción en sus ex colonias para garantizar su presencia económica y militar en la zona, lo que requiere la preservación de los negocios de las eт.

- La permisividad legal/real según países y contextos, es regada con euros/dólares para campañas políticas o para el bolsillo de los gestores públicos.

\section{Económicas}

- En determinados países, es común el ofrecimiento de tecnología e inversiones de infraestructura básicas -carreteras, puentes, líneas de ferrocarril- a cambio de recursos naturales -por ejemplo, China en África. Quizás el consumo, la sociedad y las organizaciones no tengan una capacidad mayor de lo que la ha tenido la globalización de equilibrar estas asimetrías.

- En muchas ocasiones las et textiles compradoras de producción en monopsonio -únicos compradores- presionan para bajar el precio de venta de los productos, situación que repercute en las condiciones de trabajo de la empresa contratista local.

- Las auditorías además de ser un negocio, incluso las mejores no pueden suplir la necesaria intervención sindical, particularmente los de empresa o a nivel local -de ahí la propuesta de los Ami.

- Las capacidades estatales tienen que ser mejoradas para mejorar el control y no dejar a las empresas auditarse por sí mismas.

- La normativa que regula la toxicidad de determinados productos, está basada en hallazgos científicos bastante antiguos. En muchos casos sin tener en cuenta la exposición a largo plazo, de hecho, es probable que haya importantes efectos crónicos negativos que nunca vayan a ser recogidos. Se necesitan décadas para la corrección de este ajuste.

- En determinados países productores no existe salario mínimo - no es una prioridad para las empresas, marcas de ropa y gobiernos.

- Trabajo ocasional y estacionalidad del mismo lo que genera mayores riesgos.

- Utilización de la RSE como una herramienta de marketing, que incluso puede desplazar a los sindicatos y estados -cada vez menos intervencionistas- así como a la negociación colectiva. La RSE en muchos países no es más que filantropía, beneficencia y marketing.

- Disparidad de RSE según países/intereses. 


\section{Sociales}

- La producción textil es fundamental en muchos países, de ahí que se plieguen a las exigencias de los compradores de producción. Las barreras de entrada a inversiones son menores, mayor desregulación, mayor flexibilidad además de una permisiva legislación medioambiental.

- Condiciones laborales y salariales inferiores en comparación con los países avanzados. Represión de todo tipo de reivindicación de los trabajadores, con jornadas de 12, 14 horas diarias.

- Mayor precariedad femenina que masculina.

- Ausencia por acción u omisión de un sindicalismo global. Existen gobiernos pro-empresariales. Las empresas, han avanzado en estrategias del debilitamiento -descrédito, infiltración legislativa- sindical independiente.

- Herramientas online de los consumidores orientadas al boicot, en vez de a la potenciación de las empresas más responsables. Tampoco dan la oportunidad de evaluar a su cadena de suministro, centrándose como ej. sustancias/emisiones o lista cerrada de valores.

- El fin delAcuerdo Multifibras elimina restricciones para poder elaborar e importar mercancía de países subdesarrollados, no equilibrando aspectos laborales, sociales, medioambientales y generando dumping social.

- Tejido social y de la cadena productiva textil incontrolable en países subdesarrollados o en vías de desarrollo con amplia cadena de subcontrataciones -llegando incluso a talleres a domicilio- y proveedores desde muy grandes a pequeños comerciantes locales.

- El mundo del consumo depende de los medios de comunicación, estos a su vez están dominados por el poder económico. Estos medios no sólo no cuestionan el consumo global de estas mercancías "de marca», sino que en gran medida viven de ellas a través de ingresos.Además pueden ocultar conductas irresponsables.

- Malas condiciones de vida para trabajadores, baja calidad en el alojamiento, instalaciones comunales y falta de actividades sociales/ocio.

- Para las empresas corruptas, el coste de trabajar bajo esos procedimientos es menor que el cumplimiento de sus obligaciones legales.

\section{Tecnológicas}

- El etiquetado de las prendas debe de ser $100 \%$ fiable, accesible y entendible -no necesariamente en la prenda, al poder contener centenares de productos, pero si online- conteniendo todos los productos, proveedores y procesos llevados en ellas. En la normativa europea no hay obligatoriedad de incluir en el etiquetado de las prendas textiles alguna de las sustancias incluidas en la lista REACH -unas 160-, sólo se informará a los consumidores en caso de pregunta. La ciudadanía no tiene herramientas para defender sus derechos.

- Los países avanzados tecnológicamente, tienen una posición privilegiada dentro de los procesos de globalización laboral, situación que no evita la desaparición de desigualdades sociales.

- Muchos de los estudios independientes o de grupos de investigación sobre sustancias tóxicas son rechazados al no seguir criterios GLP -más costosos y por tanto sólo al alcance de la mano de la industria.

- Los centros de producción no pueden o no quieren cambiar el sistema tradicional de producción a un nuevo sistema donde la tecnología juega un gran papel o por no tener dinero para invertir o por resistencia.

- El principal problema de los tintes es medioambiental, muchos de ellos acaban en el desagüe además de utilizarse gran cantidad de agua y productos auxiliares en el procesamiento textil. La legislación y control es exiguo.

- Solo se podrían imputar responsabilidades a las empresas por el uso de productos tóxicos, si las evidencias científicas son capaces de rastrear los efectos adversos producidos por la utilización de las mismas por parte de las empresas textiles, algo difícil, caro -de demostrar para ong's- y sin interés real para la industria o gobiernos.

- Los límites máximos de exposición a sustancias químicas nocivas no los ponen las multinacionales, sino las agencias públicas, pudiendo estar sujetas a presiones políticas o empresariales.

- El lógico avance tecnológico de creación y producción textil,en muchos casos, no evalúan los riesgos y secuelas como esquilmación de recursos naturales o nuevos modelos sociales. 


\section{CONCLUSIONES}

La sociedad demanda conocer si se elaboran productos textiles de una manera no sólo legal sino también responsable. Esta situación ha resultado ser crítica y preocupante en la actualidad; afecta de manera directa a países avanzados -deslocalizaciones, dumping social, etc.-, países en vías de desarrollo o subdesarrollados y entorno natural.

La sostenibilidad y equidad del sistema productivo textil debe de articularse con herramientas de presente y futuro.

Las empresas son necesarias, crean riqueza y en algunos $\operatorname{casos}^{3}$ la distribuyen mediante sus impuestos, producción e investigación. Las empresas exploran todos los límites legales y organizativos posibles con varias finalidades, principalmente el ahorro de costes aunque también evitar legislaciones más rígidas o sindicatos relativamente articulados como pasa en Europa. La sociedad mira hacia el futuro abrazada a procesos evolutivos y tecnológicos relacionados paralelamente con un consumo en masa y en muchos casos innecesario, principalmente en los países avanzados. Este sentimiento ha sido bien articulado por las grandes marcas, ávidas de negocio, que tienen la capacidad de generar deseos y necesidades artificiales de las que pueden derivarse desigualdades y el esclavismo del siglo xxI, como es la precariedad laboral a través de relaciones laborales efímeras.

Hoy en día «las fronteras ya no existen», al menos en relación a la libre circulación de capitales. Esta circunstancia tiene como fin la exploración de los límites de la productividad con un único denominador común, el capital y la maximización de beneficios concentrados detrás de los procesos de mundialización. Las empresas disfrutan de derechos y obligaciones a medida: autocertificaciones, normativas impulsadas por ellas mismas, límites de contaminación ilimitados -hoy día pueden ser externalizadoslos cuales son políticamente reforzados y científicamente evidenciados. La gestión de estas conductas irresponsables ha acabado formando parte del «cajón de sastre» de la Rse; de ahí que muchos de los expertos consultados coincidan en cuestiones de responsabilidad: si las empresas deben de ser éticas, las relaciones entre corrupción, política y grandes élites empresariales, así como su afectación a la cadena de valor.

La identificación de las debilidades dentro del sector textil tiene la finalidad de contribuir al desarrollo industrial textil de una manera ética y sostenible. Es necesario y posible minimizar cualquier tipo de abuso empresarial

3 Según Oxfam-Intermón «Las familias aportan casi 50 veces más a las arcas públicas que las grandes empresas» (2014). 
o estatal, sea por acción u omisión, a través de un diseño y evaluación de las correctas políticas de RSE. Debido a sus ilimitadas dimensiones, focalizamos nuestras conclusiones en diferentes áreas, a la vez que proponemos diversas líneas de acción a modo de posibles medidas de respuesta y equilibrio.

\subsection{Globalización}

No estamos en contra de la globalización sino de cómo se produce y en qué condiciones. Por sí mismo, el término parece sugerir un cierto sentido de igualdad, globalidad, uniformidad; pero la situación actual del marco textil se asemeja más bien a una estructura piramidal, por las desiguales concentraciones de poder, derechos y beneficios en cada uno de sus estratos. De ahí que sea más apropiado el término mundialización, en el cual se connota la distribución de determinadas acciones de afectación -la concentración de beneficios o la dependencia de los trabajadores y pueblos de las ET- en mayor o menor medida de manera desigual, por acción u omisión, sobre todo en países en vías de desarrollo, donde las políticas de monopsonio textil están asentadas. Los procesos de mundialización han posibilitado la externalización de procesos industriales por parte de las empresas, y de responsabilidades de los estados; al coincidir la acción legislativa internacional con la acción comercial de determinados grupos empresariales, llegan incluso a eliminar o ignorar normativas de carácter fiscal, asistencial, ecológica o sindical. De aquí se deriva una depreciación de la mano de obra en los países avanzados - al no poder competir con países subdesarrollados-, a la vez que un aumento de la oferta de mano de obra cada vez más técnica, en los subdesarrollados, aunque con desigualdades manifiestas. Todo ello unido a procesos de gamificación ${ }^{4}$ en los cuales los propios trabajadores son presionados a correr en contra del cronómetro, y la conservación del puesto de trabajo depende, además, de la continua puesta en escena de la productividad de tus compañeros.

Todavía no existen estados transnacionales con capacidad suficiente de regulación y control de las ET textiles. Hablar de legislación laboral y seguridad sigue siendo una utopía para muchos trabajadores y sindicalistas hoy en día. Aunque la situación es, de hecho, corregible, el grueso de los políticos y empresarios no tienen interés en hacerlo, ya que cada mejora

4 Articulo orientado a «la mejora de las capacidades del ser humano a través de la evaluación cuantitativa sistemática» (Gueguen, 2015). 
en el sistema, pese a suponer céntimos de incremento en el coste final de las prendas, prácticamente imperceptibles para la inmensa sociedad, a la larga son millones de euros que ninguna empresa, gobierno o mafia están dispuestos a perder o ceder.

La sociedad reclama compromisos vinculantes. Una pequeña parte tiene la capacidad de condenar a través de su compra a determinadas compañías. Este efecto está limitado y contrarrestado por poderes como el económico, el político e inclusive el de los medios de comunicación, que en muchos casos forman parte del mismo conglomerado, tanto por acción a través de participación en empresas o a través de la publicidad que realizan en ellos; hoy son un poder sin contrapoder, puesto al servicio del entramado textil. La globalización ha quedado al servicio de unos pocos.

\subsection{Empresas y proveedores}

Las ET utilizan recursos productivos o jurídicos, zonas de libre comercio o débiles sistemas sociales que garanticen un beneficio extremo; así, una vez cumplida la legislación de los países de destino -elaborada con tiralíneas a la baja, pueden expandirse con total libertad. Todo ello unido a un gran sentimiento de gratitud y ansia de recepción de inversiones por parte de los países subdesarrollados, concretado en tratados bilaterales, de libre comercio o multilaterales. Ya no importan las diferencias culturales o lazos de una empresa con sus filiales; allí donde haya oportunidad de negocio, allí se acude, y ya se arreglará cualquier contratiempo de la mejor manera. La «mejor manera» que han encontrado los gobernantes, empresarios y algunos sindicatos se conoce como RSE. Aunque pueden existir otras, como enviar a las familias reales a modo de embajadores (Sánchez, 1999; Fernández, 2013; Esteban Lario, 2014) con la finalidad de conseguir objetivos e intentar arreglar con gestos lo que no son capaces de arreglar los gobernantes con legislaciones mínimas que protejan igualmente a los ciudadanos, por muy remotos que sean los lugares donde se desarrolla la actividad industrial, del mismo modo que se protege el comercio.

\subsection{ONG's y medio ambiente}

Las organizaciones no gubernamentales actúan como contrapoder en defensa de la ciudadanía y del medio ambiente. Es habitual observar abusos 
o apropiaciones del medio ambiente por parte de ETs o estados que por el simple permiso de explotación imponen sus procedimientos como ideario, en muchos casos sin ningún tipo de control real y efectivo, desarrollando una actitud cuasi delictiva. Paralelamente, muchas empresas minimizan su responsabilidad o quedan prácticamente en mano de la providencia, a través de costosísimos sistemas de peritaje y arbitraje internacional que no todos los afectados pueden costearse. De ahí que sea necesario articular procedimientos que regulen la deuda ecológica ${ }^{5}$ de gobiernos y ETs, así como una correcta persecución, publicación y sanción de los delitos medioambientales, acorde con los perjuicios causados derivados de su actividad. Un plan de prevención medioambiental de carácter global debería articularse y ejecutarse, acrecentándose su urgencia en la medida que siguen intensificándose los ritmos de producción-contaminación (Naredo, 1999; Descamps, 2015).

Recientemente hemos conocido un estudio ${ }^{6}$ que alerta sobre las causas del descenso de $\mathrm{CO}_{2}$, señalando que era la crisis, y no el aumento del uso del gas natural, la causante de la reducción de gases del efecto invernadero. Klaus Hubaceck, uno de los autores de dicho estudio, señala un cambio estructural que «también refleja la deslocalización progresiva de las industrias con uso intensivo de emisiones a China y otros países en desarrollo» (2015), en otras palabras, los países ricos externalizan su contaminación y fabrican productos sucios en otros países como China.

Pese a quedar clara la unanimidad por parte de los participantes en relación a la existencia de ongs y su valor ${ }^{7}$ (den Hond y de Bakker, 2007; King y Pearce, 2010; Cardona, 2012), en ocasiones se prestan a acciones de impacto mediático más que a transformaciones y mejoras sustanciales. Esta situación debe de ser corregida si pretenden seguir siendo una palanca de cambio transparente y necesario. En relación con la transparencia exigida a

5 La deuda ecológica, según J. Martínez Alier (2004), es la deuda acumulada por los países del norte hacia los países del sur por dos razones. En primer lugar, las exportaciones de productos primarios a precios muy bajos, es decir sin incluir los daños ambientales producidos en el lugar de la extracción y del procesamiento, ni la contaminación a escala global. En segundo lugar, por la ocupación gratuita o muy barata de espacio ambiental la atmósfera, el agua, la tierra al depositar los residuos productivos.

6 Estudio publicado por S. Kuishuang y otros, en 2015 en Nature Communications pone en evidencia la opinión de muchos gobiernos y multinacionales que señalaban que el descenso de las emisiones de gases de efecto invernadero se debía a la reducción progresiva de la descarbonización dentro del sistema energético, cosa alejada de la realidad, según nuestro análisis, en el cual la reducción de emisiones se ha debido principalmente a la recesión económica, mientras que la menor utilización de carbón jugó un papel mucho menor.

7 La ONG Igualdad Animal vincula a firmas de ropa con granjas que maltratan a conejos (Bow, 2015). 
todos los agentes implicados en el sector textil, a los que se le exige transparencia, Mulet ${ }^{8}$ señala:

\begin{abstract}
Respecto a las ONG, se podría aplicar el mismo criterio ya que la mayoría también son multinacionales, pero mucho más opacas. Por ejemplo ¿Cuánto cobra un alto ejecutivo de Greenpeace o Friends of Earth? El modelo ong habría que replantearlo, partiendo de la base que la mayoría se financian únicamente por fondos públicos, lo que contradice su definición. De hecho el problema de las ongs es que muchas de sus campañas no se basan en solucionar problemas, sino en buscar impactos mediáticos para captar la atención y publicidad gratuita (2015).
\end{abstract}

\title{
4.4. Sindicalismo
}

El sindicalismo y por ende los métodos de representación colectiva se encuentran en horas aciagas. Al respecto de las legislaciones laborales débiles, Oliván (2015) expresa que «los sindicatos no son capaces de entender que el núcleo de esa gente explotada ya no tiene siquiera la condición de trabajadores, circunstancia no exclusiva de los países avanzados»"

En países subdesarrollados o en vías de desarrollo, el solo hecho de mentar a los sindicatos produce escalofríos ${ }^{10}$ (Maihack, 2014). Ni que decir tiene que para muchos trabajadores es casi imposible ejercer sus derechos en tales circunstancias (Frank, 2015). Sobre la situación actual de la representación colectiva, Hernández ${ }^{11}$ (2015) señala:

El problema es que los sindicatos se han debilitado por varias razones: 1) por la falta de representación auténtica, 2) porque no han sabido entender los cambios globales y las

8 J. M Mulet y F. Oliván (06 de 2015). Documentación propia extraída de un análisis DELPHI/entrevista al autor por (A. Luque, entrevistador) e incluida en la tesis «Gestión y control de la cadena de valor dentro del sector textil en países en vías de desarrollo, hacia los límites de la logística y el outsourcing: Ética o Estética».

9 «Becarios a coste cero en la onv: Un joven neozelandés desató la polémica sobre el trato reservado a los interinos en Ginebra» (Constantini, 2015).

10 Los trabajadores del sector textil de la industria en Bangladesh se enfrentan a condiciones laborales precarias y tácticas antisindicales por parte de empleadores, como agresiones contra quienes organizan sindicatos o despidos. Estas prácticas han sido denunciadas por Human Rights Watch en un informe de 78 páginas del año 2015 titulado «Whoever Raises Their Head, Suffers the Most': Workers' Rights in Bangladesh's Garment Factories», pese a que la oIт (2013) está intentando sentar las bases para «Mejorar las condiciones de trabajo en la industria del vestido: Progresos y resultados», también destaca la creación de un fondo conjunto a través de un comité de coordinación por el desastre de Raná Plaza en Bangladesh (Rana Plaza Arragement, 2015).

11 A. Hernández, M. Aguirre y A. Orsatti (07 de 2015). Documentación propia extraída de un analisis DELPHI/entrevista a los autores por (A. Luque, entrevistador) e incluida en la tesis «Gestión y control de la cadena de valor dentro del sector textil en países en vías de desarrollo, hacia los límites de la logística y el outsourcing: Ética o Estética». 
nuevas formas que tendrían que aprender para organizarse en el contexto de la globalización y 3) porque, en efecto, de manera deliberada los gobiernos pro-empresariales y las empresas han avanzado estrategias - de desacreditación, infiltración pero también legislativas- de debilitamiento de los sindicatos independientes y auténticos.

La razón de fabricar o subcontratar en determinados países -subdesarrollados, en vías de desarrollo, etc.- es evitar a los sindicatos de países avanzados. Por eso, en este contexto, cualquier medida de atenuación normativa a través de rse tendrá poca cabida, al menos desde el punto de vista legal y ético. Las relaciones laborales están en proceso de descomposición, alentadas en muchos casos por una mejora imparable de beneficios, así como por el crecimiento de los procesos de externalización del trabajo. Para Aguirre (2015) el sindicalismo «avanza hacia su cuasi desaparición, debido especialmente a la subcontratación múltiple. Es necesario buscar formas de sindicalismo para los subcontratados/trabajadores no fijos, y con formas transnacionales». En determinados países, las relaciones contractuales de trabajo son verbales, con lo que se articulan y destruyen velozmente, según nos ha señalado el investigador y ex embajador de Italia en la India e Irán,Toscano:

Me parece evidente que el sindicalismo ha sido derrotado en el mundo más desarrollado, y prácticamente no existe en el menos desarrollado: en la India el 90 por ciento de los trabajadores son «informales» - ni contrato de trabajo, ni derechos, ni sindicatos (2015).

En relación a los AET como vía de mejora -acuerdos de empresa transnacionales firmados entre multinacionales y federaciones sindicales de carácter global- Orsatti señala:

Comparativamente con el universo de empresas transnacionales, la aplicación de tales instrumentos [intergubernamentales como directrices de la OCDE, Declaración Tripartita de la ort, Principios sobre Derechos Humanos de la un o tribunales éticos en América Latina] es insignificante en extensión, sin descontar que representan un leve avance en la exploración de formas de acción social y de difusión del tema -los «casos» ante las Directrices de la OCDE no superan los 250, los acuerdos marco no superan los 200, la Declaración de оाт apenas se ha aplicado en una docena de episodios (2015).

Existiendo unos 200 acuerdos marco internacionales (AMT), si es ese el camino, ¿son suficientes?, ¿`su clausulado es equilibrado? Con relación a las organizaciones sindicales, Palazuelos ${ }^{12}$ señala que:

12 E. Palazuelos y A. Teitelbaum (07 de 2015). Documentación propia extraída de un análisis DELPHI/ entrevista a los autores por (A. Luque, entrevistador) e incluida en la tesis «Gestión y control de la cadena de valor dentro del sector textil en países en vías de desarrollo, hacia los límites de la logística y el outsourcing: Ética o Estética». 
Los sindicatos son necesarios y requieren de un replanteamiento profundo de sus objetivos, estructuras y funcionamiento; pero ese replanteamiento no es menor que el que deben tener tanto las políticas económicas de los gobiernos como las organizaciones internacionales -existentes o por crear ex novo- para afrontar los retos existentes en la economía mundial (2015).

Hoy en día son organizaciones en muchos casos estériles, sin capacidad de acción/reacción al no conocer o disponer de las verdaderas herramientas necesarias para impulsar un cambio hacia las mejoras de los trabajadores, no solo textiles. ¿Cómo? Por ejemplo, dejando de parapetarse detrás de determinados partidos políticos y empresas a cambio de prebendas, publicando sus sueldos, cometidos y funciones, etc.

Según Teitelbaum:

El sindicalismo en general hace rato que ha renunciado a promover cambios radicales que lleven a la suprimir la explotación capitalista y se conforma con exigir algunas mejoras, que ni siquiera son duraderas. Esto se agrava por la inexistencia de una solidaridad internacional entre los trabajadores de los países desarrollados y los de los países pobres, pues se hallan en situación de objetiva competencia en razón de la profunda desigualdad de los salarios a pesar de una productividad semejante (2015).

\subsection{Legislación}

La legislación debe de ser un elemento estructural sobre el cual pivoten otra serie de acciones en convivencia con la misma (Sebastio, 2014). De hecho, situaciones de solidez normativa nacional e internacional aumentan la seguridad jurídica y evitan abusos ${ }^{13}$ indirectos (Chakravarthi, 2004). No es el caso de importantes contextos textiles normativos en los países subdesarrollados o en vías de desarrollo, por ejemplo Bangladesh o Myanmar, según Human Rights Watch (2015). Elaborar una normativa a medida, prácticamente sin cortapisas ni límites, no es legalidad aunque hoy día sigue siendo posible (Tokman, 2001). Este es el vértice en el cual se amparan las ETS textiles para seguir produciendo en situaciones de manifiesta injusticia social (Ryder, 2015). Así disponen de un amplio abanico de fuerza laboral «a la carta», inclusive en connivencia con determinados estados empujados de manera directa a mirar hacia otro lado, cuando se habla de derechos laborales o de ratificación de convenios de la oIT. Legislando, o no legislando

13 Informe de Oxfam Intermón, «La ilusión fiscal: demasiadas sombras en la fiscalidad de las grandes empresas» (2015). 
(Sánchez Barrilao, 2004), estos estados se "cruzan de brazos» ante inversiones que en determinados casos beneficiarán a muchos de sus mismos gobernantes-dueños, como ha sido el caso en Rana Plaza de Bangladesh (Navarro, 2013).

El nivel de permisividad por parte de los poderes ejecutivo, legislativo o judicial en relación a la manera de actuar de las empresas multinacionales, transnacionales -químicas/textiles- es tan grande, indican Beck (1998) y Zabalo (2006), que acaban transfiriendo esa legitimidad ilegítima a las empresas, convirtiéndolas en semiestados (Beck, 2000), en muchos casos con su propio gobierno corporativo y contactos al máximo nivel entre directivos de alto rango, o presidentes y primeros ministros de estos países $^{14}$. La maximización del beneficio, como ideario, es la norma actual. Por tanto, cualquier ilimitación legal del mercado es bienvenida como señalan Ramonet (2009) y Gotzsche (2014). Tal es el caso de los lobbies y determinadas corporaciones que someten a la ue y determinados gobiernos a intereses particulares (Brown, 1998; Folch, 1998; Kwame Sundaram, 2009).

\subsection{Riesgos químicos y toxicidad}

Podemos afirmar que la seguridad y controles aplicados al sector textil son hoy en día los más seguros y modernos conocidos hasta el momento (Aular, 2013). Muchos de los participantes han sido proclives hacia la afirmación de que esa circunstancia es un problema político y no científico.

Cabe señalar, como así se recoge en diferentes citas y estudios referenciados de la presente investigación, que muchas de las normas actuales que regulan las sustancias químicas que pueden utilizarse o no en los procesos de fabricación textil son anticuadas. Los procedimientos de actualización deben mejorarse, siendo el camino de mejora la inversión en ciencia, además de aplicar una mayor transparencia. Existe baja integración de evidencias científicas sobre la toxicidad de los compuestos:

Las normas actuales se basan en los hallazgos científicos bastante viejos. Muchos de esos estudios de toxicología fueron pruebas pasadas de moda que simplemente indicaban sí un animal expuesto a una sustancia química moría inmediatamente o al menos pronto. Esto no tiene en cuenta la salud y la calidad de vida de los animales expuestos en el largo plazo. De hecho, es probable que haya importantes efectos crónicos negativos que nunca

14 «Pablo Isla no da puntada sin hilo en China: El presidente de Inditex se reúne con miembros del gobierno del gigante asiático en su visita a un mercado clave para su compañía» (Vázquez, 2015). 
vayan a ser recogidos en las pruebas de toxicología -supervivencia- de roedores (Wat$\left.\operatorname{son}^{15}, 2015\right)$.

En relación a los disruptores endocrinos ${ }^{16}$, estos deben de ser identificados de manera correcta y estudiados, destacando diferentes estudios como los de Fernández, Olmos, y Olea (2007), Olea, (2009), y Repetto y Repetto (2009). Como señala la experta en el área, Romano:

Los efectos de las sustancias tóxicas bioacumulativas son especialmente preocupantes ya que al no metabolizarse o hacerlo de forma muy lenta pueden causar sus efectos tóxicos durante más tiempo.Además, la acumulación en animales que sirven de alimento da lugar a la exposición de la población (2015).

Los expertos consultados están en su mayoría de acuerdo en que estudios más exhaustivos, mejores métodos de análisis e información, tienen la capacidad de reducir los costes en sanidad así como los riesgos para las personas. El avance científico textil asentado en gran parte a través de la innovación química, no puede considerarse como daño colateral científico, sino que se debe de operar con máxima transparencia atendiendo a recomendaciones de expertos, asumiendo que los organismos colegiados que regulan el uso de determinadas sustancias no garantizan su infalibilidad. Existe consenso a la hora de señalar la necesidad de dotar al consumidor el derecho a conocer todos y cada uno de los compuestos de las prendas textiles. Técnicamente es posible dotar a la etiqueta de un código que pueda consultarse en internet siendo superior ese derecho al secreto industrial alegado.

El camino para mejorar la seguridad de los consumidores y riesgos de los trabajadores, en opinión de los expertos, consistiría en el establecimiento de estrategias multisectoriales - para reducir la exposición y minimizar el riesgo de determinadas sustancias- avanzando en criterios y estándares de protección de la salud de los trabajadores y de la población general, evitando el uso de sustancias más peligrosas en países con una legislación más débil. Luongo en una investigación titulada Los productos químicos

15 C. S. Watson y D. Romano, (07 de 2015). Documentación propia extraída de un analisis DELPHI/ entrevista a la autora por (A. Luque, entrevistador) e incluida en la tesis «Gestión y control de la cadena de valor dentro del sector textil en países en vías de desarrollo, hacia los límites de la logística y el outsourcing: Ética o Estética».

16 «os efectos de los DE [disruptores endocrinos] se producen a dosis muy bajas, en general muy por debajo de los límites de exposición legalmente establecidos. Estamos expuestos a los DE en nuestros lugares de trabajo, pero también en nuestros hogares por la contaminación de alimentos con plaguicidas, la exposición a productos plásticos y a plastificantes, el uso de algunos detergentes y por la contaminación del medio ambiente» (Aular, 2013). 
en los textiles: Una fuente potencial de exposición para los bumanos y la contaminación ambiental se señala que «[...] el algodón orgánico y el etiquetado ecológico no son ninguna garantía de que los textiles están libres de productos químicos nocivos» (2015:37).

\subsection{Estudios de impacto}

Es necesaria la utilización de un lenguaje apropiado y real, sin enmascaramientos por parte de los sujetos relacionados. Ante la aparición de un riesgo emergente, no puede sustentarse cualquier negativa institucional o empresarial sobre el argumento de la falta de estudios de impacto con muestras representativas, cuando ni siquiera se conocen muchos de los componentes utilizados ${ }^{17}$. Los riesgos químicos ${ }^{18}$ y laborales existen pese a que no hayan sido reconocidos por determinados organismos públicos o empresas (Martí Valls, 2011). Las organizaciones empresariales no invierten ni facilitan actuaciones contrarias a sus beneficios, de hecho fomentan estudios favorables a sus intereses ${ }^{19}$. Los estados han quedado grandes para las cosas pequeñas y pequeños para las cosas grandes, de ahí su falta de autoridad y en muchos casos de legitimidad, al estar transferidas sus competencias a organismos supranacionales imperfectos, cediendo con ello soberanía (Bodemer, 1998; Rodríguez, 1999). A modo de ejemplo, las investigaciones de la Universidad de Granada o CREAL explicando los riesgos de determinadas sustancias químicas son más que evidentes. Estos riesgos no deben ser ignorados por el mero hecho de ser publicados a través de un sistema paralegal o con menos recursos, ya que si se dispone de menos medios materiales y humanos no es por voluntad propia de la comunidad

17 La revista Environmental Health Perspectives (2015), la conocida como «Declaración de Madrid», en la que más de 200 científicos muestran su preocupación por los compuestos químicos per y polifluorados. En este documento se pone de manifiesto la escasa información remitida por los fabricantes sobre las estructuras y perfiles toxicológicos de los PFCs presentes en el mercado.

18 "Chemicals in textiles: Risks to human health and the environment» (KEMI Swedish Chemicals Agency, 2014).

19 Un estudio patrocinado por el National Textile Center (Wang y otros, 2002) a través de ocho universidades de Carolina del Norte investigaron la estabilidad térmica de los textiles, específicamente con respecto a los antioxidantes utilizados en los acabados. Se investigaron cuatro antioxidantes diferentes uno de los cuales se basa en el bisfenol A. Según Oecotextiles (2011) el bisfenol A se utiliza en la producción de los retardantes de llama, y como intermediario en la fabricación de polímeros, fungicidas, antioxidantes, y colorantes. Debido a su utilización como un producto intermedio, es difícil de precisar, además los fabricantes textiles mantienen sus componentes secretos, con lo que no se podrá saber su composición real -a menos que alguien financie un estudio. 
investigadora, sino más bien, en muchos casos, por presión de los intereses de quienes se podrían ver afectados con los resultados de dichos estudios.

\subsection{Desempleo, derechos humanos y sociales}

El nivel de desempleo y la externalización-subcontratación de servicios textiles condicionan el nuevo paradigma económico y social. Actualmente, las empresas pueden obtener beneficios récord, a la vez que se suprimen puestos de trabajo y se minimizan las condiciones laborales de los mismos. Es posible crear una estructura de miles de trabajadores con un solo ordenador, capital, conexión a internet y poco más, el resto ya lo ofrece el mercado. Hoy en día existen más riesgos al respecto que nunca; no sólo hablamos de la acumulación de capital por una ínfima parte de la población mundial, sino que el capital genera más capital sin necesidad de la fuerza del trabajo, lo que para el común de los mortales es considerado como una economía de casino (Navarro y otros, 2011; Navarro, 2015). Eso tiene una ventaja competitiva sideral, sobre todo si se realiza una fotografía en ese momento -imagen realizada con asiduidad por muchas escuelas de negocios. En este caso, realizando una imagen panorámica y transversal del sector textil, esta nos genera incertidumbres. Es necesario analizar de manera ética y económica si una empresa debe utilizar mano laboral a la carta, subvenciones o prebendas estatales para sus objetivos a la vez que se externalizan esos costes derivados.

Las empresas deben ser responsables y realizar la actividad laboral con el mismo respeto y condiciones éticas -y a ser posible mismos materialesque en el mal llamado primer mundo, interiorizando per se sus valores y los que la sociedad espera de ellos. Las situaciones de aprovechamiento antiético por parte de las ETS y gobiernos, deben ser reconocidas, denunciadas, perseguidas y castigadas.

\subsection{RsE}

La RSE en el sector textil -como muchas otras recomendaciones- busca mejorar las prácticas empresariales así como su relación con todos los grupos de interés, con la finalidad de obtener resultados tangibles que contribuyan a una mejora social en general. Esta idea, sustentada por ejemplo por los Principios Rectores, entre otros, no buscan elementos vinculantes ni los 
ordenan, no limitan la responsabilidad extraterritorial de las ETs, ni tampoco recogen de manera real ni eficaz la responsabilidad jurídica de las cadenas de suministro o los mecanismos desplegados -de acción y corrección- en relación a los DDHH. Las ETS buscan generar impacto positivo a un menor coste, además intentan reconvertirlo a modo de inversión. Para las empresas, siempre resultará más conveniente ser ellas quienes delimitan ese coste, en lugar de que les sea impuesto por la sociedad a través de la ley. En esto actúan como si ellas mismas dictaran la medida de la ley y de la trampa, cometiendo los abusos e indultándose o prescribiéndose ellas mismas la sanción, según su propia conveniencia. Recordemos, además, que decir «las empresas» refiere una figura formal cuyas decisiones, comportamientos y beneficios derivan, a fin de cuentas, en personas singulares concretas.

Las empresas no hacen todo lo posible por integrarse o conocer la cultura en los países donde desarrollan la actividad industrial, de hecho abusan de su posición de fuerza. Sus departamentos de comunicación tampoco se comportan en muchos casos de manera ética, sino que utilizan la Rsc de manera instrumental. Desde hace algunos años existe una práctica comunicacional muy extendida entre grandes empresas y algunos organismos oficiales, basada en el be friendly de las redes sociales. En la mayoría de los casos no va más allá de generar el «milagro» a través de las redes sociales: cómo hacer que todos piensen que las cosas cambian mientras todo sigue igual pero con followers y RSE.

La argumentación esgrimida por determinadas empresas textiles, la cual es discutible y endeble, unida a la ocultación de información y empoderamiento paulatino de las mismas, nada tiene que ver con el objeto de la RSE, sino que resulta contraproducente. Las preguntas, aunque no se respondan, tienen respuesta. Queda claro el abuso de las empresas e instituciones, a través de estas circunstancias, en beneficio propio ¿O es posible pensar que si la legislación fuera superior a la RSE esta existiría?

Una circunstancia es ayudar a mejorar la legislación existente -publicando los medios y esfuerzos de tal acción- y otra diferente es aprovecharse de la legislación vigente o ser esta muy endeble para intentar travestir la RSE a rango de ley. El presente de las Eт textiles no puede obviar preceptos fundamentales como son el cumplimiento y promoción real de los DDHH. No se puede pretender mejorar aspectos que afectan a derechos fundamentales a través de la RSE, AMI o el "poder» del consumidor a través de sus anémicas herramientas. 


\section{LÍNEAS DE ACCIÓN}

El funcionamiento de la industria textil debe conjugar de manera responsable la realización de su finalidad comercial con su ineludible función social. Es decir, desarrollar su productividad y rentabilidad en condiciones éticas de seguridad, dignidad, igualdad y sostenibilidad, reportando beneficios para todas las partes involucradas. Esta circunstancia, más allá de ser deseable, es posible y debe de ser de obligado cumplimiento

Por ello y una vez analizadas las debilidades aportadas por los expertos, se proponen un conjunto de acciones que pueden ayudar a mejorar las condiciones en las que las ет trabajan en diferentes contextos:

1) Las eт textiles no pueden ni deben producir en países en los que se vulneran los derechos humanos ${ }^{20}$. Un predictor de primer nivel es la ratificación de convenios de la ort por parte de los países en donde se quiere producir.

2) Establecer responsabilidad solidaria extraterritorial de las ET tanto para sus proveedores, filiales, subcontratas, licenciatarias así como todo tipo de tiralíneas jurídicos ${ }^{21}$ que tengan relación por acción $\mathrm{u}$ omisión con los productos y/o servicios producidos.

3) Vinculación de tratados comerciales bilaterales, multilaterales, de libre comercio, etc., a jueces y tribunales públicos con la finalidad de generar transparencia, certidumbre y equidad sin generar menoscabo a la soberanía de los estados.

4) Responsabilidad de los estados y corporaciones ante la falta de diligencia de las Ет. Los poderes públicos tienen la obligación de prevenir, investigar y castigar. Los estados no pueden estar impermeabilizados de responsabilidades ante un mercado con fallos y sin regulación efectiva (Tirole, 2005).

5) Las auditorias pueden ser necesarias si son reguladas por parte de los poderes públicos. La experiencia alerta sobre el negocio de las mismas y en muchos casos su discutida efectividad.

6) Establecimiento de protocolos con capacidad sancionadora que protejan al medio ambiente, a los seres vivos y a las personas. Destacamos la utilidad y posible pertinencia de una inspección medioambiental

20 El embajador de Bangladesh, acusado de crímenes de lesa humanidad, presenta credenciales ante el Rey (Europapress, 2015).

21 «Inditex ha derivado al menos 2.000 millones en beneficios a una pequeña unidad operativa en Países Bajos y Suiza. Esta empresa sólo emplea a un $0,1 \%$ de la plantilla mundial de Inditex, pero ha publicado al menos el 20\% del beneficio de la empresa matriz el año pasado» (Drucker, 2014). 
de carácter global con carácter sancionatorio y precautorio de carácter internacional. Igualmente se publicarán las sanciones si las hubiere y serán de carácter público y global.

7) Criterios de selección en las ет basados en la rectitud moral, la ética y los valores, no únicamente en las capacidades profesionales ${ }^{22}$ económicas.

8) Las agencias de (des)calificación son una herramienta que puede ser utilizada de manera positiva, aunque igualmente se pueden ensalzar los aspectos negativos como señala Pereyra $(2013)^{23}$. Su dependencia privada generalmente a través de fundaciones, patronatos, empresas, etc., con intereses concretos, posibilita que la evaluación de la información recogida se aleje de los cánones de solidaridad y objetividad. La falta de detalle del $100 \%$ de los ingresos de las agencias de calificación que se autoproclaman transparentes o su modo de financiarse, las convierte de facto en la contrafigura de la misma. Por tanto, se propone una agencia de calificación dependiente de organismos públicos multisectoriales sin intereses económicos directos con capacidad objetiva de garantizar pulcritud, voluntad y esfuerzos realizados por parte de la agencia -supranacional- evaluadora en relación a las calificaciones realizadas sobre la transparencia, seguridad e idoneidad de los países analizados así como del cumplimiento y respeto de los DDHH de las partes afectadas.

9) El lenguaje utilizado por las empresas debe de recoger con exactitud, claridad y adecuación a una intención divulgativa y formativa de cara a la sociedad civil, las circunstancias que acontecen; como son el caso de catástrofes humanas, vertidos, etc., dándole una correcta difusión a la información en proporción con la actualidad y alcance para no convertirse en corresponsables de manera doble.

10) Los acuerdos marco internacionales (AMI), son una herramienta mediante la que se pueden democratizar -o no- las relaciones laborales dentro de las cadenas de producción globales. Pueden servir

22 El responsable de RRHн de Google en una entrevista concedida al New York Times señala que «El expediente académico no sirve para nada” (Bryant, 2013).

23 «Una de las herramientas de medición más conocidas es el Índice de Percepción de la Corrupción (CPI) elaborado por Transparencia Internacional, que permite clasificar en un ranking a casi doscientos países.Además de inducir a una confusión entre percepción y medición, el índice ha sido cuestionado porque recurre centralmente a consultoras financieras para realizar las evaluaciones, lo cual genera un fuerte sesgo que refleja lo que podríamos llamar genéricamente el punto de vista del mundo de los negocios. Según esta medición, en 2012 Argentina se ubicaba en el puesto 102, mientras que Chile, por tomar un ejemplo cercano, se ubica en el 20. ¿Argentina es un país mucho más corrupto que Chile? [...]» (Pereyra, 2013). 
de pantalla a modo de instrumento corporativo, demonizando las relaciones laborales al estar vacíos de contenido punitivo, faltos de supervisión efectiva y medios para llevarlos a cabo de manera real, autónoma y proporcional sin dependencia empresarial. Quedan de manera irremisible al arbitrio de la negociación cuasi privada y asimétrica los casos de inclusión o no de toda su cadena de producción. Se propone la independencia económica y societaria de los agentes implicados mediante una aportación anual proporcional al objeto de cobertura con mecanismos de revocabilidad, denuncia, supervisión y gestión autónoma. La orT debe de autorizar y velar su establecimiento sin ser mero observador.

11) Puesta en conocimiento de la filiación societaria de la cadena de producción global y datos de las subcontrataciones a las autoridades competentes, circunstancia debidamente protegida, con deber de sigilo -y sanción en caso de incumplimiento- para el órgano que custodie esa información.

12) El etiquetado del $100 \%$ de los productos y proveedores que contienen las prendas es de obligación fundamental y vital. Existen mecanismos para que a través de un simple código (Qr) en las etiquetas, cualquier consumidor pueda acceder mediante internet al listado de componentes de las prendas, el número de sanciones y causa de las mismas, así como la cadena completa de producción, pudiéndose usar códigos en lugar de nombres. Realmente no es el nombre de la empresa/taller subcontratado lo que el consumidor debe conocer, sino si es $100 \%$ confiable -en materia de prevención, conciliación, derechos humanos, sanciones, etc.

13) Publicidad en las sanciones a las empresas textiles incumplidoras evitando ser suministradoras de lotes a las administraciones públicas. A modo de ejemplo, no reconocer -o torpedear- los derechos de personas homosexuales, con discapacidad o excluir a mujeres ${ }^{24}$ embarazadas -circunstancias orientadas a los países frágiles- debe de ser objeto de pedagogía y de seguimiento de acciones correctoras, inclusive resolviendo el vínculo mercantil -debiendo estar previamente contemplado en el pliego de condiciones- obligando a indemnizar a la administración y sociedad por el perjuicio.

24 «Visitamos 4 fábricas, 2 del vestido y 2 del calzado. Una de cada sector en cada una de las dos zonas industriales visitadas: Ho Chi Minh City (la antigua Saigón) y Hanoi-Haiphong. El $\mathrm{n}^{\circ}$ de trabajadores por fábrica oscilaba entre 1.000 y 8.000 (una de las del calzado), con una proporción de mujeres en torno al $85 \%$ del total» (Boix y Garrido, 2015: 11). 
14) Aumento de competencias en el Tribunal Penal Internacional (TPI) sobre ет. La limitación de mecanismos jurídicos por parte de las ET como puede ser la acotación de competencias en el TPI, estableciendo jurisdicción únicamente sobre personas físicas y evitando la misma sobre las personas jurídicas, así como sobre los delitos económicos, o evitando la vinculación a las resoluciones de la orT genera una justicia de cartón piedra.

15) Los salarios de los trabajadores deben de ser dignos y han de establecerse en relación a parámetros objetivos por organismos públicos internacionales y no a recomendaciones de parte.

16) Democratización de las organizaciones internacionales. Un país un voto, para evitar que prevalezcan los abusos por parte de países con mayor músculo económico, como sucede actualmente en el Banco Mundial o FMI donde los votos son proporcionales a las contribuciones financieras, ${ }^{25} \mathrm{y}$ por tanto hay países que están subyugados de por vida legalizando con ello asimetrías normativas.

17) Control de las deudas de los países pobres. No se pueden asignar créditos -en muchos casos a través de planes de estabilidad- a sabiendas de la imposibilidad de su devolución generando comisiones leoninas, daños irreparables y una deuda diseñada indirectamente para ser irrecuperable.

18) Control de la competencia despiadada entre países a la hora de producir. No se puede competir con economías abismalmente diferentes. Se deben establecer «esclusas» que tengan la capacidad de neutralizar el dumping social.

19) Regulación efectiva de economías colaborativas como elemento socializador, de gestión de crisis económicas así como de I+D+I. La regulación en favor de las grandes corporaciones ${ }^{26}$ prohibiendo el autoconsumo, evitando compartir servicios o la creación de todo tipo de obstáculos para pequeños productores textiles, que en ninguno de los casos pueden competir con las grandes ET, debe de ser corregido y reequilibrado, evitando subsumir a parte de la sociedad en un mayor riesgo social al ser la economía colaborativa el único camino de salvación para muchos pueblos y estratos de la sociedad.

25 El rol de los Organismos Internacionales en las problemáticas contemporáneas: un estudio sobre el Banco Mundial y su posicionamiento con respecto a la pobreza (Carcedo y Calvento, 2014).

26 El 'lobby' de los fabricantes de coches se impone en el seno de la UE a la hora de modificar la legislación (Riés, 2016). 


\section{BIBLIOGRAFÍA}

Arias, M. (2003): «Metodologías de investigación emergentes en economía de la empresa», en Hirigoyen, G. y TerceÑo, A. (eds.): Evolución, revolución y saber en las organizaciones, XVII Congreso Nacional-XIII Congreso Hispano-Francés de AEDEM, Bordeaux, pp. 19-28.

Aular, Y. (2013): «Disruptores endocrinos: un nuevo informe con recomendaciones para reducir sus efectos adversos a la salud». Valencia, Salus, 17,1, pp.4-6.

BECK, U. (1998): ¿Qué es la globalización? Falacias del globalismo, respuestas a la globalización, Barcelona, Paidós, Estado y Sociedad.

- (2000): Un nuevo mundo feliz. La precariedad del trabajo en la era de la globalización, Barcelona, Paidós.

BODEMER, K. (1998): «La globalización. Un concepto y sus problemas», Nueva sociedad, 156, pp. 54-71.

Brown, L. (1998): "Retos del nuevo siglo», en The Worldwatch Institute (2000): La situación del mundo 2000, Barcelona, Icaria.

Buxmann, P. y Gebauer, J. (1999): «Evaluating the Use of Information Technology in interorganizational relationships», Systems Sciences, Procedings of 32th Annual Hawaii International Conference, track 8.

Calveras, A., y Ganuza, J. (2004): «Responsabilidad Social Corporativa. Una Visión desde la Teoría Económica», Cuadernos Económicos de ICE, 76, pp. 101-118.

CARdona, H. (2012): «Innovación y responsabilidad social: una reflexión sobre los puntos de encuentro", Revista Universidad E Empresa, 13, 21, pp. 13-35.

Chakravarthi, R. (2004): "Globalización y movimientos migratorios», Alternativas Sur, 3, 1, pp. 27-36.

Christopher, M. y otros (2006): «A taxonomy for selecting global supply chains strategies», The International Journal of Logistics Management, 17, 2, pp. 277-287.

Del Rincón, D. y otros (1995): Técnicas de investigación en Ciencias Sociales, Madrid, Dikinson.

Den Hond, F., y De BaKker, F. (2007): «Ideologically Motivated Activism: How Acitivist Groups Influence Corporate Social ChangeActivities», Academy of Management Review, 32, 3, pp. 901-924.

Echezarraga, J., y Jarillo, J. C. (2001): Estrategia Internacional más allá de la Exportación, Madrid, McGraw-Hill. 
Esteban Lario, J. (2014): Comunicación y Protocolo Empresarial en los países de la zona euro, Madrid, Dykinson.

FERNÁNDEZ, F. (2013): «El «tabú» periodístico de la monarquía en España. La crisis real y la crisis coyuntural», Revista Latina de Comunicación Social, 68, pp. 217-247.

FERNÁNDEZ, M. y otros (2007): «Exposure to endocrine disruptors and male urogenital tract malformations [cryptorchidism and hypospadias]", Gaceta Sanitaria, 21, 6, pp. 500-514.

FERNÁNDEZ-BALlESTEROS, R. (1995): Evaluación de programas: una guía práctica en ámbitos sociales, educativos y de salud, Madrid, Síntesis.

Folch, R. (1998): Ambiente, emoción y ética, Barcelona, Ariel.

GIL, I. y otros (2008): "Automatización del almacén y surtido en la distribución de productos de uso duradero», Universia Business Review, 19, pp. 118-133.

GILDIA, R. (1995): «Consumer survey confirms corporate social responsibility affects buying decisions», Public Relations Quarterly, 39, pp. 20-21.

Grzybowski, L. (2012): «¿Perjudica la mundialización al medio ambiente?» en SfEIr, M. (ed.) (2012): El Atlas de las Mundializaciones, Madrid, Fund. Mondiplo.

Guercini, S., y Runfola,A. (2004): «Sourcing strategies in clothing retail firms: product complexity versus overseas supply chain»,Journal of Costumer Behaviour, 3, 3, pp. 305-334.

Hess, M., y Yeung, H. (2006): "Whither global production networks in economic geography? Past, present, and future», Environment and Planning $A, 38,7$, pp. 1193-1204.

Heuskel, D. y Costa, C. (1999): «Estrategia en la era de la desintegración», Harvard Deusto Business Review, 93, pp. 36-45.

JóDAR, P. (1998): «Impacto de las TIC en el sector textil-confección», Informe del Observatorio Industrial del sector Textil-Confección, Madrid, Observatorio del sector Textil-Confección.

Kаннат, F. (2005): «El tema de la corrupción en la literatura en ciencia política», en Portocarrero, F. (ed.) (2005): El pacto infame: estudios sobre la corrupción en el Perú, Lima, Red para el desarrollo de las ciencias sociales en el Perú.

King, B., y Pearce, N. (2010): "The Contentiousness of Markets: Politics, Social Movements, and Institutional Change in Markets», Annual Review of Sociology, 36, pp. 249-267.

Kwame Sundaram, J. (2009): «El rol del sector privado en la lucha contra la corrupción: su importancia para afrontar los desafíos locales y mundia- 
les en materia de gobernabilidad», en (2009) Informe Global de la Corrupción 2009: Corrupción y sector privado, Cambridge, Cambridge University Press.

Landeta Rodríguez, J. (2002): El método Delphi. Una técnica de previsión del futuro, Barcelona, Ariel.

Linstone, H., y Turoff, M. (eds.) (1975): The Delphi method:Techniques and applications, Boston, Addison-Wesley.

Luna Huertas, P. y otros (2006): «Los Delphi como fundamento metodológico predictivo para la investigación en sistemas de información y tecnologías de la información (Is/It)», Pixel-Bit. Revista de Medios y Educación, 26, pp. 89-112.

Luongo, G. (2015): «Chemicals in textiles: A potential source for human exposure and environmental pollution», tesis doctoral, Stockholm, Stockholm University, disponible en: http://www.diva-portal.org/smash/ get/diva2:850089/FULLTEXT02.pdf

Martí Valls, J. (coord.) (2011): La contaminación y la salud, Centre d'Anàlisi i Programes Sanitaris (CAPS).

Martínez Piñeiro, E. (2003): «La técnica DelPhi como estrategia de consulta a los implicados en la evaluación de programas», Revista de Investigación Educativa, 21, 2, pp. 449-463.

Mengual, S. (2011): La importancia percibida por el profesorado y el alumnado sobre la inclusión de la competencia digital en educación Superior, tesis doctoral, Alicante, Universidad de Alicante.

Naredo, J. (1999): Desarrollo económico y deterioro ecológico, Madrid, Visor y Fundación Argentaria.

NAVARro, V. y otros (2011): Hay alternativas:propuestas para crear empleo $y$ bienestar social en España, Madrid, Sequitur.

Olea, N. (2009): «Disruptores endocrinos: su presencia en el medio y efectos», XV Reunión de la Sociedad Española de Química Analítica (SEQA), Donostia-San Sebastián.

PILL, J. (1971): «The Delphi method: substance, context, a critique and an annotated bibliography», Socio-Economic Planning Sciences, 5, 1, pp. 57-71.

Prahalad, C., y Hamel, G. (1990): «The Core Competence of the Corporation», Harvard Business Review, 68, 3, pp. 79-111.

Repetto, M., y Repetto, G. (2009): Toxicología fundamenta, Ediciones Díaz de Santos.

RiIsgaARD, L., y HAMmer, N. (2011): «Prospects for Labour in Global Value Chains: Labour Standards in the Cut Flower and Banana Industries», British Journal of Industrial Relations, 49, pp. 168-190. 
Risse, T. (2002): «Transnational actors and world politics», en von CARLsnaes,

W. y otros (2002): Handbook of international relations, Londres, Sage. Rodríguez, G. (1999): «Derecho internacional y globalización», Isonomía, 11, pp 23-32.

Román, B. (2004): «La corrosión del ethos corporativo: reflexiones sobre las condiciones de posibilidad de la ética empresarial», Recerca, 4, pp. 137151.

Ruiz Olabuénaga, J., y Ispizua, M. (1989): La descodificación de la vida cotidiana, Bilbao, Universidad de Deusto.

SÁNCHEZ BARRILAO, J. (2004): «Sobre la constitución normativa y la globalización», Revista de la Facultad de Derecho de la Universidad de Granada, 7, pp. 241-261.

SÁnchez, J. (1999): «El coste de la Casa Real en el Siglo XVII», Cuadernos de Estudios Empresariales, 9, pp. 87-107.

Strauss, A., y Corbin, J. (1990): Basics of Qualitative Research: Grounded Theory, procedures and techniques, California, Sage.

Tokman, V. (2001): "Políticas de empleo en la nueva era económica», Seminario La teoría del Desarrollo en los albores del siglo XXI, Santiago de Chile, CEPAL.

VAlles, M. (2014): «Entrevistas cualitativas», Cuadernos metodológicos, 32, Centro de Madrid, Investigaciones Sociológicas.

Vélez PAREJA, I. (2002): Decisiones de inversión enfocado a la valoración de empresas, Bogotá, CEJA.

Werner, K., y WeIss, H. (2006): El libro negro de las marcas, Buenos Aires, Sudamericana.

WolfT, K. (2005): «Private actors and the legitimacy of governance beyond the state: Conceptual outlines and empirical explorations», en BENZ,A. y PAPADOPOUlos, I. (eds.) (2005): Governance and democratic legitimacy, Londres, Routledge.

ZabAlo, P. (2006): «El papel de las multinacionales en la economía globalizada», Pueblos, 5, pp. 5-6.

Zaman, M., y otros (1996): «Environmental consumerism and buying preference for green products», en Riquier, C. y SHARP, B. (eds.) (1996): Southern Marketing - Theory and Applications, proceedings of the Australian Marketing Educators Conference, Adelaide, Universidad de Australia del Sur, pp. 613-626.

Ziegler, J. (2013): Destrucción Masiva: Geopolítica del hambre, Barcelona, Booket Península. 


\section{OTRAS FUENTES}

BOIX, I. y GARRIDO, V. (2015): «Vietnam 2015: Una nueva aproximación sindical IV al país, a su sindicalismo y a sus industrias de la confección y del calzado», Confederación Sindical de Comisiones Obreras, disponible en: http://industria.ccoo.es/comunes/recursos/99927/2076991-Informe_-_Vietnam_2015.pdf

Bow, J. (03 de septiembre de 2014): «Igualdad animal vincula a firmas de ropa con granjas que maltratan a conejos», El País, disponible en: http://sociedad.elpais.com/sociedad/2014/09/03/actualidad/1409735825_662861. html

Bryant, A. (19 de junio de 2013): «In Head-Hunting, Big Data May Not Be Such a Big Deal», NYTimes, disponible en: http://www.nytimes. com/2013/06/20/business/in-head-hunting-big-data-may-not-be-such-abig-deal.html? pagewanted=1\&_r=1\&smid=tw-nytimesbusiness\&partne $\mathrm{r}=$ socialflow

Carcedo, J. y Calvento, M. (2014): «El rol de los organismos internacionales en las problemáticas contemporáneas: un estudio sobre el banco mundial y su posicionamiento con respecto a la pobreza», VII Congreso de Relaciones Internacionales del Instituto de Relaciones Internacionales de la Universidad Nacional de La Plata, disponible en: http://sedici. unlp.edu.ar/bitstream/handle/10915/44489/Documento_completo. pdf? sequence $=1$

Constantini, L. (19 de agosto de 2015): «Becarios a coste cero en la ONU: Un joven neozelandés desató la polémica sobre el trato reservado a los interinos en Ginebra», $E l$ País, disponible en: http://internacional.elpais. com/internacional/2015/08/18/actualidad/1439895492_896718.html

Descamps, P. (2015): «De la ciencia a la política», Le Monde Diplomatique, 241, p. 13.

Drucker, J. (2014): «Ortega's Zara Fashions Tax Avoidance by Shifting Profits to Alps», Bloomberg, disponible en: http://www.bloomberg.com/news/ articles/2014-02-26/ortega-s-zara-fashions-tax-avoidance-by-shifting-profits-to-alps

Enviromental Health Perspectives (mayo de 2015): «The Madrid Statement on Poly- and Perfluoroalkyl Substances (PFASs)», disponible en: http://ehp. niehs.nih.gov/wp-content/uploads/123/5/ehp.1509934.alt.pdf

Europapress (2015): "El embajador de Bangladesh, acusado de crímenes de lesa humanidad, presenta credenciales ante el Rey », disponible en: 
FRANK, T. (04 de enero de 2015): «Chain restaurants are killing us: Billionaire bankers, minimum-wage toilers and the nasty truth about fast-food nation», Salon, disponible en: http://www.salon.com/2015/01/04/chain_ restaurants_are_killing_us_billionaire_bankers_minimum_wage_ toilers_and_the_nasty_truth_about_fast_food_nation/

Gotzsche, P. C. (12 de septiembre de 2014): «Las farmacéuticas extorsionan a los gobiernos», La Marea, disponible en: http://www.lamarea. com/2014/09/12/peter-c-gotzsche-las-farmaceuticas-extorsionan-los-gobiernos-con-tecnicas-mafiosas/

Gueguen, M. (2015): «Les damnés de l'hyper», Philosophie Magazine, disponible en: http://www.philomag.com/lepoque/reportage/les-damnes-delhyper-11545. http://www.europapress.es/nacional/noticia-embajadorbangladesh-acusado-crimenes-lesa-humanidad-presenta-credencialesrey-20151216153954.html

Human Rights Watch (2015): «Whoever Raises Their Head, Suffers the Most': Workers' Rights in Bangladesh's Garment Factories», disponible en: http://features.hrw.org/features/HRw_2015_reports/Bangladesh_ Garment_Factories/index.html

Kemi Swedish Chemicals Agency (2014): «Chemicals in textiles: Risks to human health and the environment», disponible en: https://www.kemi.se/ files/8040fb 7a 4f2547b7bad522c399c0b649/report6-14-chemicals-intextiles.pdf

Kuishuang, S. y otros (21 de julio de 2015): «Drivers of the us $\mathrm{CO} 2$ emissions 1997-2013», Nature Comumunications, disponible en: http://www. nature.com/ncomms/2015/150721/ncomms8714/full/ncomms8714. html

Mainack, H. (3 de novimebre de 2014): "After Rana Plaza: Bottom Up Not Top Down To Ensure Workers Safety», Social Europe, Disponible en http://www.socialeurope.eu/2014/11/rana-plaza-bottom-top-ensureworkers-safety/

Muscati, S. (12 de marzo de 2015): «Camboya:Trabajadores de la industria de la confección están desprotegidos», Human rights watch, disponible en: http://www.hrw.org/es/news/2015/03/11/camboya-trabajadores-de-la-industria-de-la-confeccion-estan-desprotegidos

NaÍm, M. (octubre de 2015): «El mundo entre comillas: Vivimos en un universo lleno de instituciones y situaciones deliberadamente diseñadas para engañar a los incautos», El País, disponible en: http://internacional. elpais.com/internacional/2015/10/10/actualidad/1444491899_543067. html 
Navarro, V. (19 de enero de 2015): «El porqué de las desigualdades: una crítica del libro de Thomas Piketty «Capital in the Twenty-First Century»», Vnavarro.org, disponible en: http://www.vnavarro.org/?p=11701

- (23 de mayo de 2013): «Lo que no se dice sobre Bangladesh», Vnavarro. org, disponible en: http://www.vnavarro.org/?p=8939\&lang=CA

Oecotextiles (2011): «Bisphenol A in textile processing?», disponible en: https://oecotextiles.wordpress.com/2011/12/16/bisphenol-a-in-textileprocessing/

OrganizaCión INTERnACIONAL Del trabajo (2013): «Mejorar las condiciones de trabajo en la industria del vestido: Progresos y resultados», disponible en: http://www.ilo.org/global/research/publications/WCMS_229105/ lang--es/index.htm

OXFAM-INTERMón (28 de mayo de 2014): «Las familias aportan casi 50 veces más a las arcas públicas que las grandes empresas», disponible en: http://www.oxfamintermon.org/es/sala-de-prensa/nota-de-prensa/familias-aportan-casi-50-veces-mas-arcas-publicas-que-grandes-empresas

— (marzo de 2015): "La ilusión fiscal: demasiadas sombras en la fiscalidad de las grandes», disponible en: http://www.oxfamintermon.org/es/quehacemos/proyectos/desigualdad/ilusion-fiscal?utm_source=ndp\&utm_ medium =medios\&utm_content $=2 \& u t m \_c a m p a i g n=I G u a l e s$

Pereyra, S. (2013): «Estado, transparencia y disputa por el poder: La corrupción como crítica de la política», Le Monde Diplomatique, 170.

Ramonet, I. (2009): «Mafias farmacéuticas», Le Monde Diplomatique, 167, p. 1.

RANA PLAZA ARRANGEMENT (2015): «Donors», disponible en: http://www.ranaplaza-arrangement.org/fund/donors

RIÉs, P. (19 de enero de 2016): «Volkswagen, Renault et le TTIP», Mediapart, disponible en: https://www.mediapart.fr/journal/economie/190116/ volkswagen-renault-et-le-ttip

Ryder, G. (27 de febrero de 2015): «Labor In The Age Of Robots», Social Europe, disponible en: http://www.socialeurope.eu/2015/02/labor-inthe-age-of-robots/

Sebastio, F. (11 de noviembre de 2014): "Industrialisation And Female Empowerment: Evidence From The Bangladeshi Garments Sector», Social Europe, disponible en: http://www.socialeurope.eu/2014/11/industrialisation-female-empowerment-evidence-bangladeshi-garmentssector/

The globe and maIl (6 de julio de 2005): «Bell Globomedia Publishing», disponible en: http://v1.theglobeandmail.com/servlet/Page/document/travel/travelDestination?goto=Muskoka 
Tirole, J. (25 de diciembre de 2005): «Sin un regulador fuerte, no hay liberalización eficaz», $E l$ País, disponible en: http://elpais.com/ diario/2005/12/25/negocio/1135520066_850215.html

VázQues, S. (29 de octubre de 2015): «Pablo Isla no da puntada sin hilo en China: El presidente de Inditex se reúne con miembros del gobierno del gigante asiático en su visita a un mercado clave para su compañía», La Voz de Galicia, disponible en: http://www.lavozdegalicia.es/noticia/economia/2015/10/29/ pablo-isla-da-puntada-hilo-china/00031446136621114241102.htm

WANG, D. y otros (2002): «Improving the Thermal Stability of Textile Processing Aids», National Textile Center, disponible en: http://internacional.elpais. com/internacional/2015/08/18/actualidad/1439895492_896718.html. 